\title{
Analysis Of Alkaloids From In Vitro And In Vivo (Natural Conditions) Samples Of Jasminum Sambac L.
}

\author{
Nikita P. Sapra ${ }^{1}$ and Himanshu A. Pandya ${ }^{2}$ \\ Department of Botany, Bioinformatics and Climate Change Impacts Management School of Sciences, \\ Gujarat University, Ahmnedabad \\ Gujarat-380009, India. \\ E-mail-ahujanikita91@gmail.com ${ }^{1}$,hapandya@gmail.com ${ }^{2}$
}

\begin{abstract}
Jasminum sambac L. is erect shrub with young shoots of ovate or elliptic glabrous simple leaves, entire margin, and acute apex with opposite arrangement, grown as an ornamental shrub in gardens and cultivated throughout the tropical and subtropical parts of India. Leaves, roots and flowers are used as lactifuge. Phytochemicals are naturally occurring in the medicinal and protect from various diseases. Phytochemicals are primary and secondary compounds. Alkaloids are naturally occurring chemical compounds containing basic nitrogen atoms. The present research is an attempt to highlight the various, qualitative analysis were conducted which determined the presence of alkaloids in Jasminum sambac Linn. (Family- Oleaceae). The concentration of alkaloids was different towards leaves and flowers in in vivo analysis as compared to different shoot extracts in in vitro analysis. Attempts were made to identify and quantify individual as well as combined capacity of some important phytochemicals to address the current requirements. Pharmacological activities of the plant reported so far are antidiabetic, anti- acne A.N.S stimulating effect. The plant screened for phytochemical constituents seemed to have the potential to act as a source of useful drugs and also to improve the health status of the consumers as a result of the presence of various compounds that are vital for good health.
\end{abstract}

Keywords: Jasminum; phytochemicals; alkaloids

\section{INTRODUCTION}

It is locally known as 'Motia' and produces white flowers with very pleasant fragrance. Jasminum sambac Ait. (Family- Oleaceae) is commonly known as Mogra. It is a famous aromatic plant cultivated all over the world. Jasminum sambac L. is a shrub with white flowers which have characteristic volatile compounds differing from Jasminum grandiflorum L. (Dadlani $\mathrm{N}$ et al., 1996). In Egypt, the flowering period of J. sambac begins in April; the flowering reaches to its climax in July and then declines in September. The buds are odorless but the flowers develop their characteristic odor during night. The fragrance of the flower is formed from glycosidic precursors by endogenous enzymatic hydrolysis just before the opening of the flowers (Watanabe $\mathrm{N}$ et al., 1993). Different glycosidic volatile precursors were previously investigated (Inagaki J. et al., 1995) (Zhang Y. et al., 1995) (Moon J. et al., 1994). The flowers are used as flavor for tea leaves to provide a characteristic jasmine impact (Ito Y. et al., 2002) (Hara Y. et al., 1995). Phytochemicals such as rutin, quercetin, isoquercetin, quercetin-3dirhamnoglycosides, $\alpha$-amyrin and $\beta$-sitisterol are reported to be present in its leaves (Asongalem, 2004). The plant attains a height of 1-2 feet in later stages. Jasminum sambac is vegetative propagated by ground layering and stem cuttings. As seeds are not formed, the vegetative propagation is the only reproductive method. Normally vegetative propagation is achieved through ground layering but it is not convenient for transportation purpose of germplasm and success rate is also very low.
J. sambac also contains absolute and essential oils that are extensively used in perfumery industry due to their fine, sweet and elegant fragrance impact. Using organic solvents to get the concrete followed by ethanol extraction to obtain the absolute one the fully bloomed flowers are extracted (Kapoor J. 1991). On the other hand, the essential oil is prepared using the method of hydro distillationsolvent extraction (Sun S. et al., 1985) and super critical carbon dioxide extraction (He C. et al., 1999). The volatile composition of $J$. sambac absolute varies depending upon the environmental conditions and the agricultural practices (Mookherjee B., et al., 1990) (Shalaby A. et al., 1989) (Singh R. et al., 1986). The major and minor volatile constituents of $J$. sambac which are absolute and essential oil necessary were previously studied (Kaiser R. 1988) (Kobayashi A. et al., 1992) (Wu C et al., 1987). The volatile composition of the headspace collected directly from the flowers (Ran et al., 2002) (Zhu et al., 1993) as well as from the concrete (Kaiser R. 1988) was also reported.

Jasmine (Jasminum) is a genus containing approximately 600 species of small trees and vines in the Family- Oleaceae. These glabrous twining shrubs are widely cultivated in gardens and easily found in forests throughout tropical Asia and warm temperature regions in Europe and Africa. Their flowers have been utilized as traditional medicines in Asia to treat many diseases including abscess, breast cancer, uterine bleeding, dermatitis and toothache. In china, the leaf arts are used for the treatment of quadriplegia gall, dysentery, and 
International Journal of Research in Advent Technology, Vol.7, No.3, March 2019

$$
\text { E-ISSN: 2321-9637 }
$$

Available online at www.ijrat.org

bellyache. According to its high medicinal value Jasminum sambac is one of the most cultivated species in many countries in Asia including Thailand (Nehius, 1968).

For the detection of bioactive principles and development, the preliminary phytochemical screening tests may be useful which subsequently may lead to drug development and discovery (Vardaraian et al., 2008). Further, these tests facilitate their quantitative estimation and qualitative separation of pharmacologically active chemical compounds.

Plant cells are highly sophisticated chemical factories, where large varieties of chemical compounds are synthesized through different pathways (Ulhe et al., 2013). Separation of active substances from crude drug is called as Extraction and it involved the use of different solvents. The choice of plant material depends on its nature and compound required being isolated. The contribution of estimating the soil of was done (Bhatt, M., et al., 2015). The dry powder of the plant is commonly used for extraction. The expanding knowledge of the phytochemical screening has revolted that existence of close relationship between chemical constituent of plants and their taxonomy status. The alkaloids, tannins, glycosides, carotenoids, polyuronoids and saponins are more important chemical constituents.

In China, besides infusing 'jasmine tea' with the flower fragrance, it is common to mix the flowers with tea in boiling water to drink. We investigated further water-soluble fraction of the flowers of Jasminum sambac L. and isolated six oilgometric iridoidal glycosides.

Extraction (as term is pharmaceutically used) is the separation of medicinally active portions of plant (and animal) tissues using selective solvents through standard procedures. The products so obtained from plant are relatively complex mixtures of metabolites, in liquid or semisolid state or (after moving the solvent) in dry powder form, and are intended for an oral or external use. These includes classes of preparations known as decoctions, infusions, fluid extracts, tinctures, pilular (semisolid) extracts or powdered extracts.
Such preparations have been popularly called galenicals, named after Galen, the secondary century Greek physician (Remington JP). Jasminum sambac L. is traditionally recommended by the Indian Ayurvedic medicines for the treatment of fever or cough, indolent ulcer, abdominal distension, diarrhea, lowering the blood glucose level, regulating menstrual flow, to clean kidney waste, inflamed and blood shot eyes.

Jasmine is a climbing, trailing and erect flowering shrub. There are both deciduous and evergreen species in Jasmine. The main beauty and uniqueness of jasmine is its fragrance, which cannot be imitated by any known synthetic aromatic chemicals and has a unique status in the perfume world.

Leaves are opposite and alternate, simple, trifoliate or pinnate; leaflets are entire. Leaves contain sambacosides A, E and F (Tanahashi, 1988).

Flowers are white, yellow or rarely reddish, sometimes solitary, cymose clusters of three to many, usually fragrant; 2 loculed with 1 to 4 erect ovules.

Fruit is a berry, rarely with separate and each having 2 seeds.

\section{MATERIALS AND METHODS \\ 2.1 Collection and authentication of plant material:}

The flowers and leaves of Jasminum sambac L. were picked early in the morning of the third week of March of 2015, (the climax of the flowering season). The flowers and leaves were collected from the different shrubs, which are genetically homogenous and equally grown in the Botanical Garden, Botany Department, University School of Sciences, Gujarat University.

\subsection{Plant extract preparation:}

The collected sample was washed thoroughly shade dried at room temperature for 10 days including flowers, leaves. The dried plant material was milled and grounded into fine powder. $10 \mathrm{gm}$ of dried plant material was taken in $100 \mathrm{ml}$ solvents was kept for 12-ve 16 hours. Extract was then filtered by

Whatman 




Fig. 1. Jasminum sambac L. plant

No.1 filter paper (Harboune et al., 2007). The extract was collected and the residue was dried overnight. And then the residue was then kept into next solution for 12-ve hours and again the whole procedure was repeated. The traces of the solvents were removed by keeping the dried extracts into a desiccator.

\subsection{Preliminary phytochemical analysis:}

Qualitative phytochemical tests for the identification of alkaloids was carried out for all the extracts by the method described (Sofowara et al., 1993)

Phytochemicals are scavengers gifted by nature to regularize disorders and cure diseases. Attempts were made to identify and quantify individual as well as combined capacity of some important phytochemicals to address the current requirements.

Chemicals tests for the screening and identification of bioactive chemical constituents in the medicinal plants under study were carried out in extracts as well as powder specimens using the standard procedures.

The analysis of phytochemicals from the Jasminum sambac L. was individually performed using qualitative tests, for alkaloids, flavonoids, Saponins, Tannins, Coumarins.

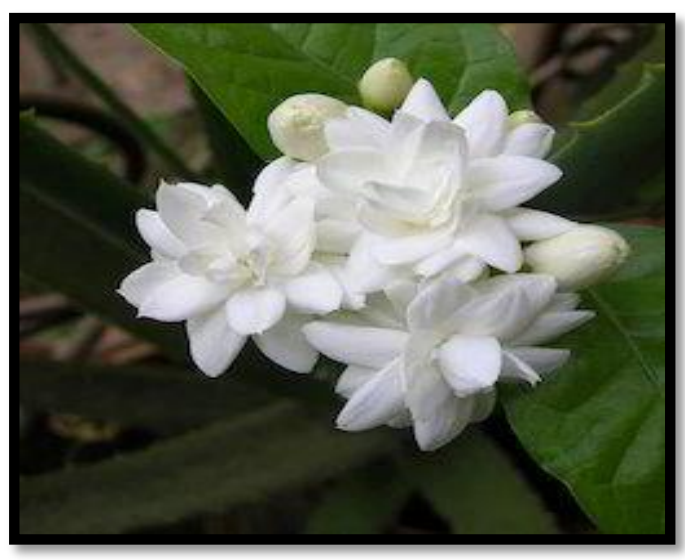

Fig. 2. Jasminum sambac L. flower

2.4 Qualitative analysis: (Manske, R. H. F. (1965) Mayer's test: $1 \mathrm{ml}$ portions of extracts was acidified with 3 drops of $1 \mathrm{M}$ hydrochloric acid and treated with 5 drops of Mayer's reagent (potassium mercuric iodide) formation of a yellow or white colored precipitate or turbidity indicated the presence of alkaloids.

2.5 Quantitative analysis: (Harborne, J. B. 1973)

$5 \mathrm{gm}$ of the sample was weighed into a $250 \mathrm{ml}$ beaker and $200 \mathrm{ml}$ of $10 \%$ acetic acid in ethanol was added and covered and allowed to stand for 4 hours. This was filtered and the extract was concentrated on water bath to one-quarter of the original volume. Concentrated ammonium hydroxide was added drop wise to the extract until the precipitation was complete. The whole solution was allowed to settle and the precipitated was collected and washed with dilute ammonium hydroxide and then filtered. The residue is the alkaloid, which was dried and weighed.

\section{RESULTS AND DISCUSSION}

Analysis involved the collection, identification, extraction, and phytochemical evaluation of extracts derives from Jasminum sambac $\mathrm{L}$ 


\subsection{In vivo phytochemical analysis of samples}

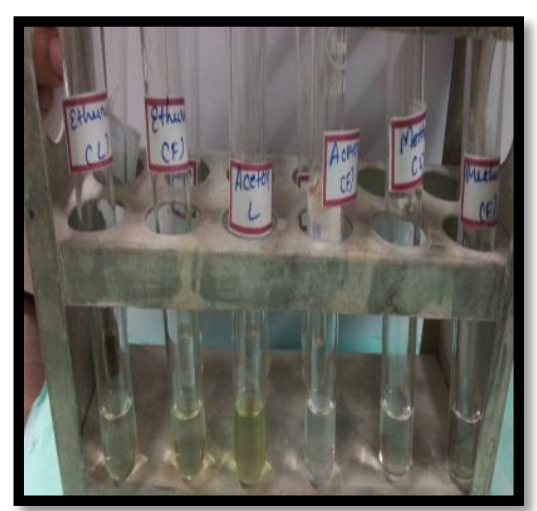

(b)

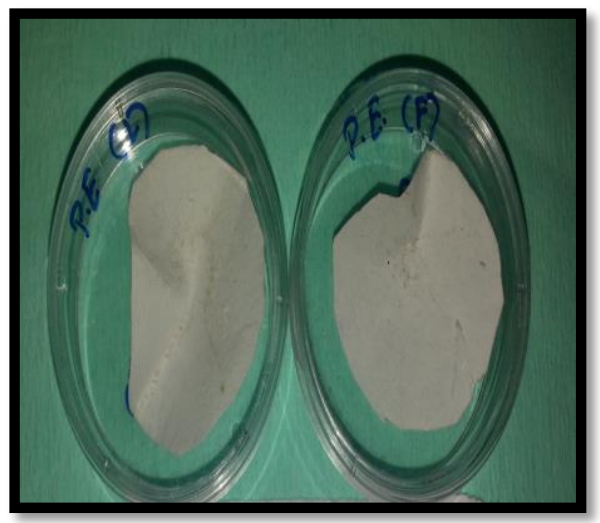

(a)

Fig. 3. Phytochemical analysis of Alkaloids

(a) Qualitative Assay (b) Quantitative Assay

Table 1. Presence of alkaloid in different extracts of Jasminum sambac L.

\begin{tabular}{|c|c|c|}
\hline Type & $\begin{array}{c}\text { Plant } \\
\text { extracts }\end{array}$ & Alkaloid \\
\hline \multirow{5}{*}{ Leaves } & Chloroform & -ve \\
\hline & Acetone & $+\mathrm{ve}$ \\
\hline & Methanol & + ve \\
\hline & Ethanol & $+\mathrm{ve}$ \\
\hline & $\begin{array}{l}\text { Petroleum } \\
\text { ether }\end{array}$ & -ve \\
\hline \multirow{5}{*}{ Flowers } & Chloroform & -ve \\
\hline & Acetone & -ve \\
\hline & Methanol & $+\mathrm{ve}$ \\
\hline & Ethanol & $+\mathrm{ve}$ \\
\hline & $\begin{array}{l}\text { Petroleum } \\
\text { ether }\end{array}$ & -ve \\
\hline
\end{tabular}

The results of the phytochemical analysis of the leaves and flowers extracts in various solvents has shown a remarkable variation in the presence of the above studied phytochemical compounds in the studied taxa. The detailed investigations of phytochemicals in various solvents are shown in Table 1.

In Petroleum ether extract, alkaloid was absent in both leaves and flowers extract of Chloroform. While alkaloid was present in leaves and absent in flowers extract of acetone. On the other hand, in methanol extracts of both leaves and flowers alkaloid was present. Same way, alkaloid was present in ethanol extract of leaves and flowers.
Lastly, it also revealed that alkaloid was absent in both the extracts of leaves and flowers.

Alkaloids are naturally occurring chemical compounds containing basic nitrogen atoms. The name derives from the word alkaline and was used to describe any nitrogen- containing base. Many alkaloids can be purified from crude extracts by acid-base extraction. They often have pharmacological effects and are used as medications, as recreational drugs, or in entheogenic rituals.

Various biologically active compounds with strong pharmacological activity are the plants belonging to family Oleaceae. These species contain very important compounds like alkaloids, flavonoids, 


\section{Available online at www.ijrat.org}

tannins and so on. Alkaloids, steroids, flavonoids, tannins were reported to have cytotoxicity in different cell lines (Kalaisevi et al., 2011). Phytochemical screening and anti-lipid peroxidation effect of Jasminum sambac and the results showed that there were presences of alkaloid, flavonoids, proteins, carbohydrates, terpenoids, tannins, Saponins, phytosterols. Methanol extract from Jasminum sambac have in vitro antimicrobial antioxidant activities, which could support the use of plant by traditional healers to treat various infectious diseases (Gopalkrishan et al., 2012).

Table 2. Quantitative analysis of Jasminum sambac L.

\begin{tabular}{|c|l|l|l|l|}
\multicolumn{1}{r}{ Type } & \multicolumn{1}{c}{ Sample Name } & \multicolumn{1}{c}{$\begin{array}{c}\text { Pre-weight } \\
(\mathbf{m g})\end{array}$} & $\begin{array}{c}\text { Post weight } \\
(\mathbf{m g})\end{array}$ & \multicolumn{1}{c|}{$\begin{array}{c}\text { Difference } \\
(\mathbf{m g})\end{array}$} \\
\hline \multirow{5}{*}{ Flowers } & Petroleum ether & 2.760 & 2.760 & 0.0 \\
\cline { 2 - 5 } & Methanol & 2.760 & 2.770 & 0.010 \\
\cline { 2 - 5 } & Ethanol & 2.750 & 2.750 & 0.0 \\
\cline { 2 - 5 } & Acetone & 2.760 & 2.770 & 0.010 \\
\cline { 2 - 5 } & Chloroform & 2.760 & 2.770 & 0.010 \\
\hline \multirow{5}{*}{ Leaves } & Petroleum ether & 2.750 & 2.750 & 0.0 \\
\cline { 2 - 5 } & Methanol & 2.760 & 2.760 & 0.0 \\
\cline { 2 - 5 } & Ethanol & 2.750 & 2.760 & 0.010 \\
\cline { 2 - 5 } & Acetone & 2.760 & 2.770 & 0.010 \\
\cline { 2 - 5 } & Chloroform & 2.780 & 2.770 & 0.010 \\
\hline
\end{tabular}

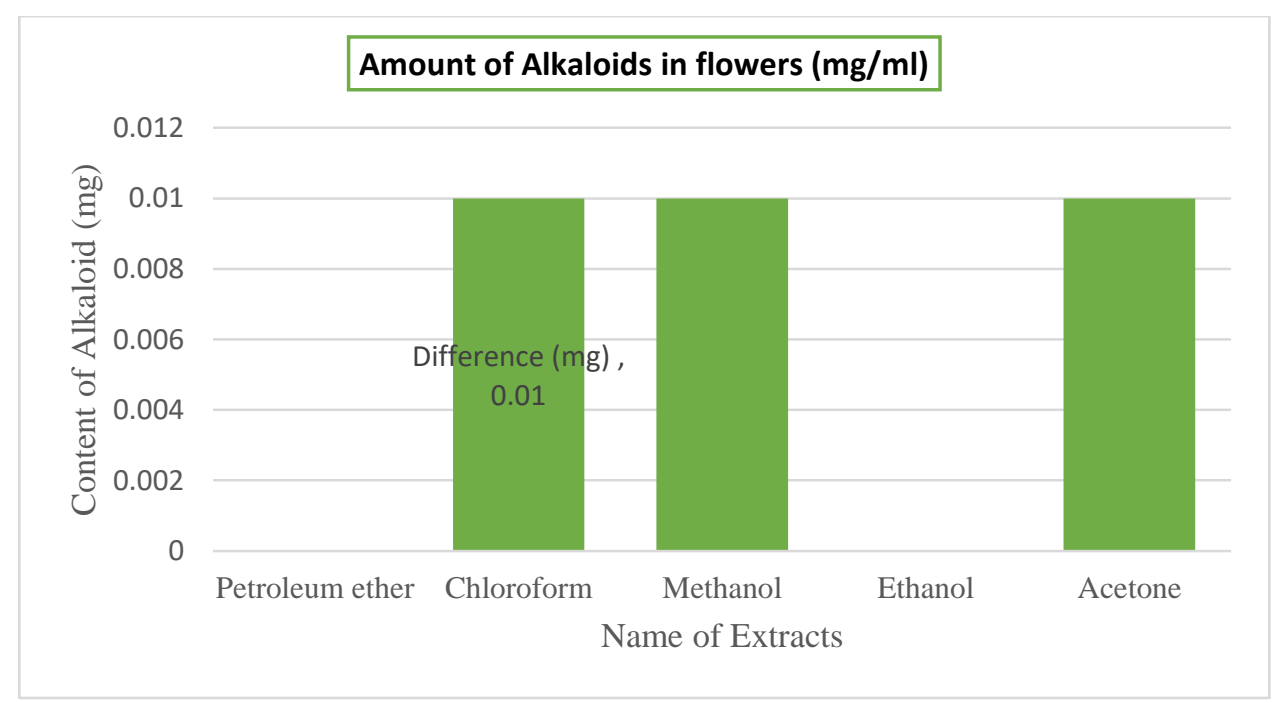

Fig. 4. Quantity of Alkaloids present in Flowers

In in vivo analysis of $J$. sambac the amount alkaloids present in polar and non-polar solvents differ from each other. Non-Polar solvents i.e. Petroleum ether and Chloroform are showing variation in the quantity of alkaloids present. In petroleum ether alkaloid is absent whereas I chloroform the amount of alkaloid present is 0.010 $\mathrm{mg} / \mathrm{ml}$ which shows huge variation in non-polar solvents itself. While in polar solvent i.e. Ethanol, Methanol and Acetone the content of alkaloid in methanol and acetone is same i.e. $0.010 \mathrm{mg} / \mathrm{ml}$ whereas in ethanol the alkaloid is absent. 
Available online at www.ijrat.org

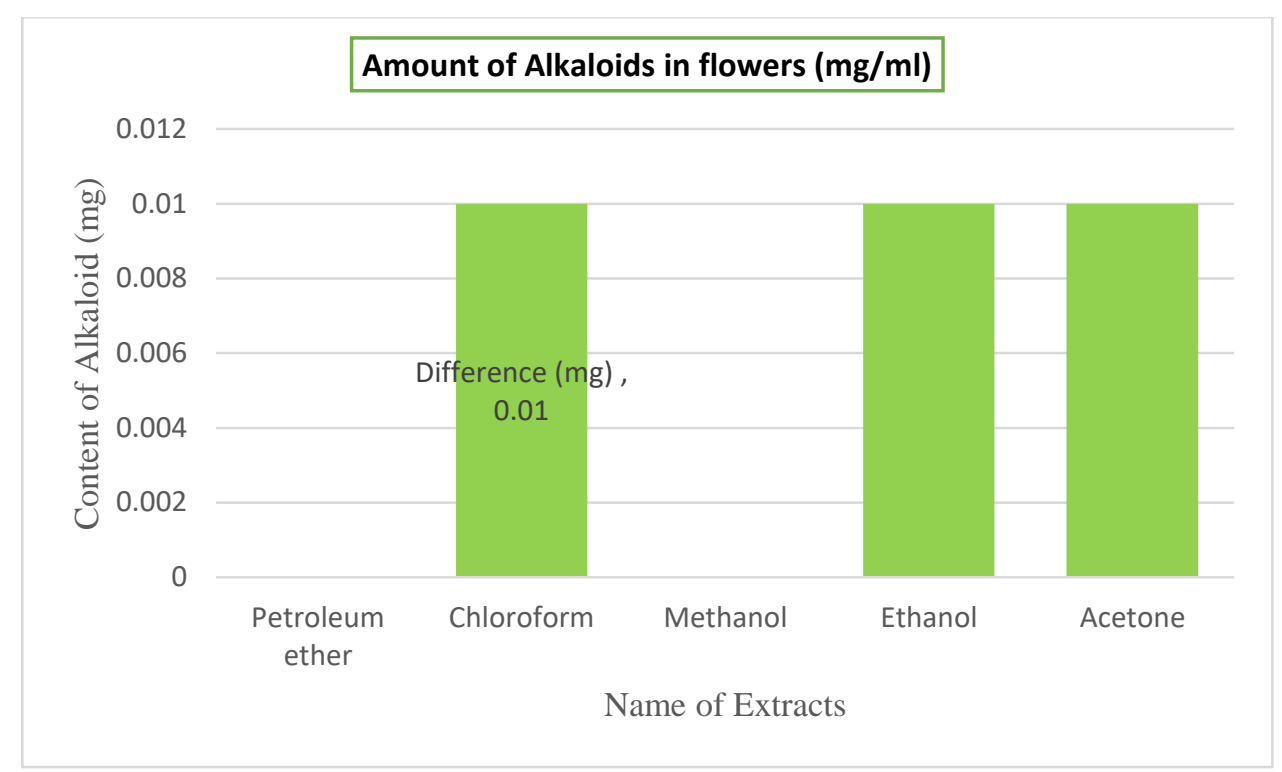

Fig. 5. Quantity of Alkaloids present in Leaves

In in vivo analysis of $J$. sambac the amount alkaloids present in polar and non-polar solvents shows variation. Non-Polar solvents i.e. Petroleum ether and Chloroform are showing variation in the quantity of alkaloids present. In petroleum ether the alkaloid is absent whereas in chloroform it is 0.010 $\mathrm{mg} / \mathrm{ml}$ which is comparatively higher. While in polar solvents i.e. ethanol, methanol and acetone the content of alkaloid is same in acetone and ethanol i.e. $0.010 \mathrm{mg} / \mathrm{ml}$ whereas in methanol the alkaloid is absent.
The importance of alkaloids, Saponins and tannins in various anti biotics used in treating common pathogenic strains has recently been reported by (Kubmarawa, 2007; Mensah, 2008) reports alkaloids in 12 leafy vegetables studied. (Ayitey et al., 1977) and earlier recorded that bitter leaf contains an alkaloid contains an alkaloid which is capable of reducing headaches associated with hypertension.

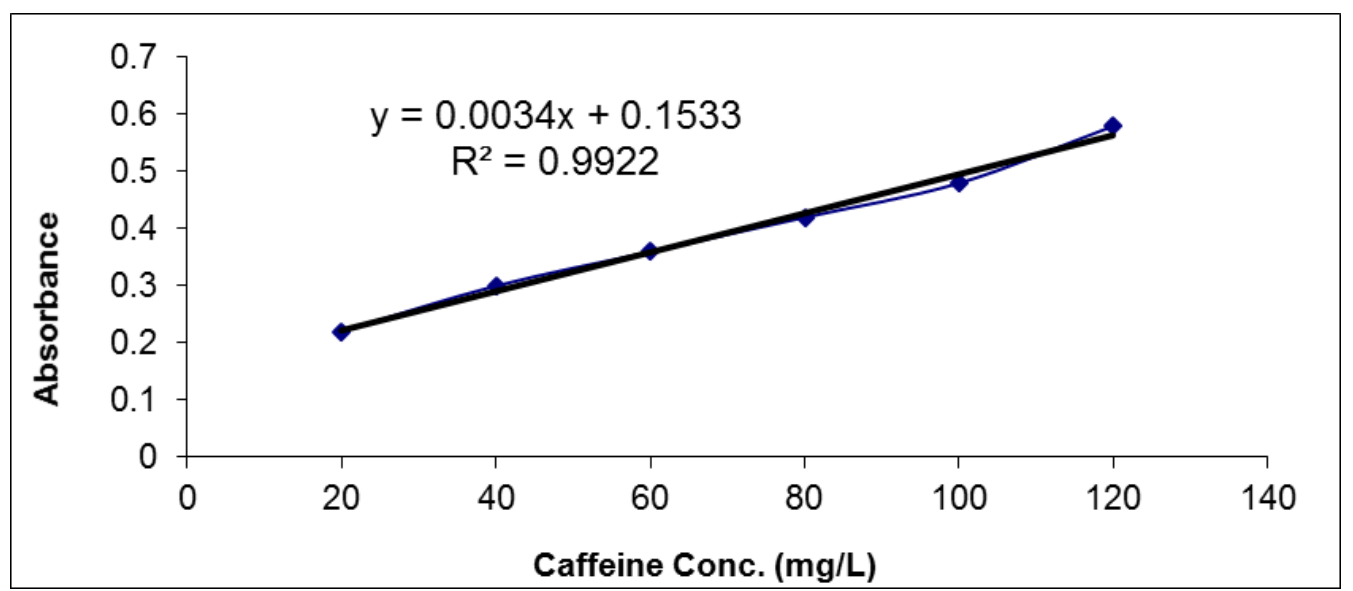

Fig. 6. Standard Curve of Caffeine 
International Journal of Research in Advent Technology, Vol.7, No.3, March 2019 E-ISSN: 2321-9637

Available online at www.ijrat.org

\subsection{In vitro phytochemical analysis of samples}

Table 3. Qualitative tests of alkaloid in different extracts of Jasminum sambac L.

\begin{tabular}{|l|l|l|l|}
\hline No. & \multicolumn{1}{|c|}{$\begin{array}{r}\text { Type of } \\
\text { extract }\end{array}$} & \multicolumn{1}{|c|}{ Solvent } & Alkaloid \\
\hline 1 & \multirow{2}{*}{ Shoot } & Ethanol & + \\
\cline { 1 - 1 } 2 & & Petroleum ether & + \\
\hline 3 & & Chloroform & + \\
\hline
\end{tabular}

$+=$ Present,$-=$ Absent

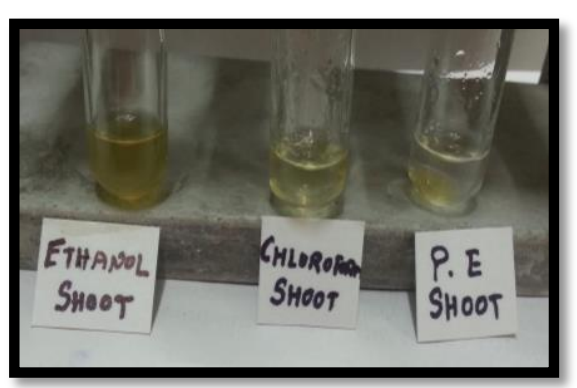

(a.)

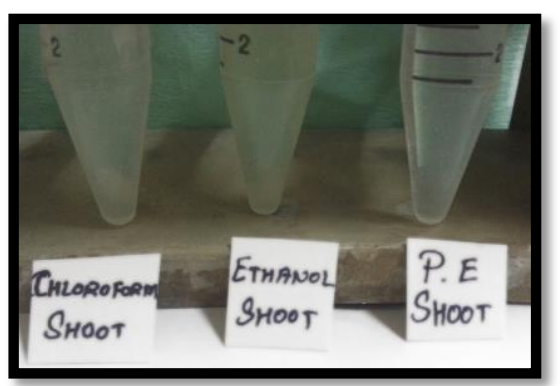

(b.)

Fig. 7. Phytochemical analysis of Alkaloids

(a) Qualitative Assay (b) Quantitative Assay

Table 4. Quantitative tests of Alkaloids

\begin{tabular}{|l|l|l|l|l|l|}
\hline No. & Type & \multicolumn{1}{|c|}{$\begin{array}{c}\text { Sample } \\
\text { Name }\end{array}$} & $\begin{array}{c}\text { Pre- } \\
\text { weight } \\
(\mathbf{m g})\end{array}$ & $\begin{array}{c}\text { Post } \\
\text { weight } \\
(\mathbf{m g})\end{array}$ & $\begin{array}{c}\text { Difference } \\
(\mathbf{m g} / \mathbf{m l})\end{array}$ \\
\hline $\mathbf{1}$ & \multirow{2}{*}{ Shoot } & $\begin{array}{l}\text { Petroleum } \\
\text { Ether }\end{array}$ & 5.530 & 5.535 & 0.005 \\
\hline $\mathbf{2}$ & & Ethanol & 5.508 & 5.511 & 0.003 \\
\hline $\mathbf{3}$ & & Chloroform & 5.619 & 5.694 & 0.075 \\
\hline
\end{tabular}



Fig. 8. Quantity of Alkaloids present in Shoot

In in vitro analysis of $J$. sambac the amount alkaloids present in polar and non-polar solvents differ from each other. Non-Polar solvents i.e.
Petroleum ether and Chloroform are showing variation in the quantity of alkaloids present. In petroleum ether the amount of alkaloid is 
International Journal of Research in Advent Technology, Vol.7, No.3, March 2019

$$
\text { E-ISSN: 2321-9637 }
$$

Available online at www.ijrat.org

$0.005 \mathrm{mg} / \mathrm{ml}$ which is higher than that of chloroform which is $0.075 \mathrm{mg} / \mathrm{ml}$ which is comparatively less. While in polar solvent i.e. Ethanol the content of alkaloid is the lowest which is $0.003 \mathrm{mg} / \mathrm{ml}$.

Jasminum sambac L. is one of the most wellfamous fragrant plants worldwide and has been prescribed in folk medicines in many countries according to its multipurpose actions. In addition, Jasmine tea is the most famous scented tea in many countries including China, Japan and Thailand. Nevertheless, the chemical constituents and pharmacological activities of Jasminum sambac L. have been rarely reported.

The ethanolic extract of Jasminum multiflorum and Jasminum officinale were found to contain alkaloids, leucoanthocyanins, steroids and coumarins (Patil et al., 2012). Terpenoids, tannins, emodin and phlobatannins are found in Jasminum officinale. Anthocyanins are not present in ethanolic extract of both plants. Chloroform extract of Jasminum multiflorum and Jasminum officinale were found to contain alkaloids, flavonoids, steroids and Saponins. Terpenoids and tannins are detected in Jasminum multiflorum and present in Jasminum officinale. Leucoanthocyanins and phlobatannins are absent in leaves of both plants.

Phytochemical compounds such as steroids, reducing sugars, triterpenoids, sugars, alkaloids, phenolic compounds, flavonoids, saponins, tannins, anthroquinones and amino acids were screened in five ferns extracts. Among these compounds alkaloids, phenolic compounds, flavonoids, Saponins and tannins are important secondary metabolites and are responsible principles for medicinal values of the respective plant. These five compounds were present in all the extracts except $P$. multiaurita. Tannins were not present in $P$. multiaurita extract. All the extracts were subjected to further analytical tests for the quantification of phytochemical compounds (Pragada et al., 2011).

\section{CONCLUSION}

Thus, from the present study the leaf extracts and flower extracts of Jasminum sambac L. showed an abundant production of phytochemicals as a secondary metabolite and they can be used in the pharmaceutical industries as a source of useful fruits and also to improve health status of the consumers as a result of the presence of various compounds that are vital for good health.

These findings suggested that Jasminum sambac L. could be a potential source of natural antioxidant having great importance as therapeutic agent and preventing oxidative stress related degenerative diseases. The comparative phytochemical studies of both field grown (in vivo) and in vitro plantlets of Jasminum sambac L. revealed the potency of phytocomponents from chloroform, acetone and ethanol extracts in in vivo analysis and from ethanolic extracts in in vitro analysis.

The Jasminum sambac L. can provide lead molecules which could be useful substrate for the synthesis of new broad-spectrum antibiotics for the treatment of infectious caused by the organisms. Further purification, identification and characterization of the active compounds would be our priority in future studies.

\section{ACKNOWLEDGEMENT}

I would like to thank Prof. (Dr.) Hitesh A. Solanki for identification and authentication of plant which is affiliated to Botany Department under the voucher specimen no.: $\mathrm{Gu} / \mathrm{Bot} / \mathrm{J} 40$ which was deposited to the museum of Botany Department, University School of Sciences, Gujarat University, Ahmedabad, India.

\section{REFERENCES}

[1] A. Kumaran, and R. Joel Karunakaran. "In vitro antioxidant activities of methanol extracts of five Phyllanthus species from India." LWT-Food Science and Technology 40, 2: 344-352, 2007.

[2] Abdoul-Latif, Fatouma, Prosper Edou, François Eba, Nabil Mohamed, Adwa Ali, Samatar Djama, Louis-Clément Obame, Ismael Bassolé, and Mamoudou Dicko. "Antimicrobial and antioxidant activities of essential oil and methanol extract of Jasminum sambac from Djibouti." African Journal of Plant Science 4, 3: 38-43, 2010.

[3] E. A. Asongalem, H. S. Foyet, S. Ekobo, T. Dimo, and P. Kamtchouing. "Antiinflammatory, lack of central analgesia and antipyretic properties of Acanthus montanus (Ness) $\mathrm{T}$. Anderson." Journal ethnopharmacology 95, 1: 63-68, 2004.

[4] M. Bhatt, and N. Sapra. "Estimates of Total Nitrogen Availability in Forest Soil Types Of Gujarat." International Journal of Recent Scientific Research 6, 2: 27602765, 2015.

[5] T. K. Biswas, and B.Mukherjee. "Plant medicines of Indian origin for wound healing activity: a review." The International Journal of Lower Extremity Wounds 2, 1: 25-39, 2003.

[6] Y. Hara, "Processing of tea." Food Rev. Int. 11: 426-430, 1995. 
International Journal of Research in Advent Technology, Vol.7, No.3, March 2019

$$
\text { E-ISSN: 2321-9637 }
$$

Available online at www.ijrat.org

[7] J. B. Harborne. Phytochemical methods chapman and Hall. Ltd. London, 4, 49188, 1973.

[8] J. M. Harris, and P. S. J. Spencer. "New Apparatus: A Modified Plethysmographic Apparatus For Recording Volume Changes In The Rat Paw." Journal of Pharmacy and Pharmacology 14, 1: 464466, 1962.

[9] He, Chunmao, Zhongyun Liang, and Hong Liu. "Study on chemical constituents of jasmine absolute extracted by supercritical carbon dioxide." Natural Product Research and Development 11,3: 53-56,1999.

[10] B. Ibrahim, A. Sowemimo, A. van Rooyen, and M. Van de Venter. "Antiinflammatory, analgesic and antioxidant activities of Cyathula prostrata (Linn.) Blume (Amaranthaceae)." Journal of ethnopharmacology 141, 1: 282-289, 2012.

[11] J. Inagaki, N. Watanabe, J. H. Moon, A. Yagi, K. Sakata, K. Ina, and S. Luo. "Glycosidic aroma precursors of 2phenylethyl and benzyl alcohols from Jasminum sambac flowers." Bioscience, biotechnology, and biochemistry 59, 4: 738-739, 1995.

[12] Y. Ito, A. Sugimoto, T. Kakuda, and K. Kubota. "Identification of potent odorants in Chinese jasmine green tea scented with flowers of Jasminum sambac." Journal of agricultural and food chemistry 50, 17: 4878-4884, 2002.

[13] Kaiser, R. "New volatile constituents of Jasminum sambac (L.) Aiton." Developments in food science 668-684, 1988.

[14] B. Kapoor, "Attars of India-A unique aroma." Perfumer \& flavorist 16, 1: 21-24, 1991.

[15] N. K. Dadlani, T. A. More, and B. Singh. "Variability and correlation studies in Jasminum." Indian Journal of Agricultural Research 30, 2: 133-141, 1996.

[16] E. Sugawara, T. Ito, S. Odagiri, K. Kubota, and A. Kobayashi. "Comparison of compositions of odor components of natto and cooked soybeans." Agricultural and Biological Chemistry 49, 2: 311-317, 1985.

[17] D. Krishnaiah, R. Sarbatly, and A. Bono. "Phytochemical antioxidants for health and medicine a move towards nature." Biotechnology and Molecular Biology Reviews 2, 4: 97-104, 2007.

[18] R. H. F. Manske, "Alkaloids of Pseudocinchona and Yohimbe." In The Alkaloids: Chemistry and Physiology. 8, 693-723. Academic Press, 1965.

[19] B. D. Mookherjee, R. W. Trenkle, and R. A. Wilson. "The chemistry of flowers, fruits and spices: live vs. dead-a new dimension in fragrance research." Pure and Applied Chemistry 62, 7: 1357-1364, 1990.

[20] J. H. Moon, N. Watanabe, K. Sakata,J. Inagaki, A. Yagi, K. Ina, and S. Luo. "Linalyl $\beta$-d-glucopyranoside and its 6'-Omalonate as aroma precursors from Jasminum sambac." Phytochemistry 36, 6: 1435-1437, 1994.

[21] R. B. Nair, B. Ravishankar, N. P. Vijayan, C. K. Sasikala, and V. N. Saraswathy. "Anti-inflammatory effect of Strbilanthus heyneanus leaves-A biochemical study." J Res Ay Sid 9, 1-2: 46, 1988.

[22] P. Tiwari, B. Kumar, M. Kaur, G. Kaur, and H. Kaur. "Phytochemical screening and extraction: a review." Internationale pharmaceutica sciencia 1, 1: 98-106, 2011.

[23] A. S. Shalaby, A. H. Hassan, A. E. Agina, and H. Abdel - amid. "Effect of nitrogen fertilization on growth, flower and concrete oil yield of Jasminum sambac. Ait." Indian Perfumer 33, 3: 268-273, 1989.

[24] T. Tanahashi, N. Nagakura, K. Inoue, and H. Inouye. "Sambacosides A, E and F, novel tetrameric iridoid glucosides from Jasminum sambac." Tetrahedron Letters 29, 15: 1793-1796, 1988.

[25] L. Zhu, Y. Li, B. Li, B. Lu, and N. Xia. "Aromatic plants and essential constituents. South China Institute of Botany, Chinese Academy of Science." Hai Feng Publisher Co, distributed by Peace Book Co Ltd, Hong 
Available online at www.ijrat.org

Kong. Also reviewed by Lawrence $B$ (1994) Perfum Flavor 19: 64-69, 1993.

[26] R. Pragada, V. Vangepurapu, S. R. Ethadi, and V. S. Praneeth. "Phytochemical investigation and in vitro antioxidant, antimicrobial activity of different fractions of Acalypha indica Linn." Int J Pharm Pharm Sci 3, 4: 314-317, 2011. 